University of Nebraska - Lincoln

DigitalCommons@University of Nebraska - Lincoln

USDA Wildlife Services - Staff Publications

U.S. Department of Agriculture: Animal and Plant Health Inspection Service

2008

\title{
An Integrated Vehicle-Mounted Telemetry System for VHF Telemetry Applications
}

\author{
Jason Gilsdorf \\ University of Nebraska-Lincoln \\ Kurt C. VerCauteren \\ USDA-APHIS-Wildlife Services, kurt.c.vercauteren@usda.gov \\ Scott E. Hygnstrom \\ University of Nebraska-Lincoln, shygnstrom1@unl.edu \\ W. David Walter \\ USDA-APHIS-Wildlife Services \\ Justin Boner \\ University of Nebraska-Lincoln, jboner@conservationfund.org
}

See next page for additional authors

Follow this and additional works at: https://digitalcommons.unl.edu/icwdm_usdanwrc

Part of the Environmental Sciences Commons

Gilsdorf, Jason; VerCauteren, Kurt C.; Hygnstrom, Scott E.; Walter, W. David; Boner, Justin; and Clements, Greg, "An Integrated Vehicle-Mounted Telemetry System for VHF Telemetry Applications" (2008). USDA Wildlife Services - Staff Publications. 917.

https://digitalcommons.unl.edu/icwdm_usdanwrc/917

This Article is brought to you for free and open access by the U.S. Department of Agriculture: Animal and Plant Health Inspection Service at DigitalCommons@University of Nebraska - Lincoln. It has been accepted for inclusion in USDA Wildlife Services - Staff Publications by an authorized administrator of DigitalCommons@University of Nebraska - Lincoln. 


\section{Authors}

Jason Gilsdorf, Kurt C. VerCauteren, Scott E. Hygnstrom, W. David Walter, Justin Boner, and Greg Clements 


\title{
An Integrated Vehicle-Mounted Telemetry System for VHF Telemetry Applications
}

\author{
JASON M. GILSDORF, ${ }^{1}$ School of Natural Resources, 415 Hardin Hall, University of Nebraska, Lincoln, NE 68583-0974, USA \\ KURT C. VERCAUTEREN, ${ }^{2}$ United States Department of Agriculture/Animal and Plant Health Inspection Services/Wildife Services, \\ National Wildlife Research Center, 4101 LaPorte Avenue, Fort Collins, CO 80521-2154, USA \\ SCOTT E. HYGNSTROM, School of Natural Resources, 415 Hardin Hall, University of Nebraska, Lincoln, NE 68583-0974, USA \\ W. DAVID WALTER, United States Department of Agriculture/Animal and Plant Health Inspection Services/Wildife Services, \\ National Wildlife Research Center, 4101 LaPorte Avenue, Fort Collins, CO 80521-2154, USA \\ JUSTIN R. BONER, School of Natural Resources, 415 Hardin Hall, University of Nebraska, Lincoln, NE 68583-0974, USA \\ GREG M. CLEMENTS, School of Natural Resources, 415 Hardin Hall, University of Nebraska, Lincoln, NE 68583-0974, USA
}

\begin{abstract}
We designed and developed a vehicle-mounted very high frequency-based telemetry system that integrated an on-board antenna, receiver, electronic compass, Global Positioning System, computer, and Geographic Information System. The system allows users to accurately and quickly obtain fixes, estimate and confirm locations of radiomarked animals, and immediately record data into an electronic spreadsheet or database. The total cost of materials to build the system was $\$ 7,349$ (United States currency). Mean error angle of $2.63 \pm 12.1^{\circ}$ $\left(\mathrm{SD}\right.$; range $\left.=-33.7-42.2^{\circ}\right)$ and mean location error distance of $128 \pm 91.3 \mathrm{~m}(\mathrm{SD}$; range $=0-408 \mathrm{~m})$ suggested precision and accuracy of our system were comparable to other reported systems. Mean time to record 5 bearings/test transmitter was $6.28 \pm 0.24$ minutes (SE), which is the most efficient system reported to locate animals in the field. Vehicle-mounted telemetry systems like ours provide additional value to studies that involve tracking highly mobile species because investigators need not take bearings from established receiving stations and because investigators can immediately recognize bounced signals and take additional bearings and optimize accuracy of location estimates. (JOURNAL OF WILDLIFE MANAGEMENT 72(5):1241-1246; 2008)
\end{abstract}

DOI: $10.2193 / 2007-348$

KEY WORDS accuracy, electronic compass, error angles, Geographic Information System, Global Positioning System, location error distance, precision, radiotelemetry.

Since its inception in the late 1950s radiotelemetry has undergone numerous advances (LeMunyan et al. 1959, Cochran and Lord 1963). Handheld compasses are commonly used to collect azimuths; however, compasses may substantially decrease precision of bearings (White and Garrott 1990). Compasses can also be time-consuming and undesirable in adverse weather conditions and at night (Lovallo et al. 1994). Technological improvements in electronic compasses resulted in more accurate bearings and made collecting telemetry data more efficient (Lovallo et al. 1994, Brinkman et al. 2002, Cox et al. 2002). The recent increase in the use of Global Positioning Systems (GPS) has also allowed for more accurate estimates of animal and receiver locations (D'Eon et al. 2002). More recently, computers have been incorporated into field telemetry systems to improve efficiency and accuracy. To our knowledge, however, no one has reported on the integration of all these components into a single telemetry system.

Radiotelemetry has been used to study animal behavior (Ozoga et al. 1982, Bertrand et al. 1996, Nelson and Mech 1999), activity (Ozoga and Verme 1975, Nelson and Mech 1984, Vercauteren and Hygnstrom 1998), habitat use (Mooty et al. 1987, Grund et al. 2002, Storm et al. 2007), and survival (Jones et al. 1997, Etter et al. 2002). Very high-

${ }^{1}$ Present address: United States Department of Agriculture/Animal and Plant Health Inspection Services/Wildlife Services, $9001 \mathrm{E}$ Frontage Road, Suite A, Palmer, AK 99645, USA

2 E-mail: Kurt.C.VerCauteren@aphis.usda.gov frequency (VHF) telemetry, in contrast to GPS-based technology, continues to be a practical and reliable method to study ecological relationships between wildlife and their environment. Researchers should evaluate and report precision and accuracy of their telemetry systems to ensure that reliable data are collected (Withey et al. 2001). Precision is the consistency of the system in terms of the standard deviation of estimated and true compass bearings (Withey et al. 2001). Accuracy is the average linear distance between estimated and actual locations (Zimmerman and Powell 1995). Increasing efficiency of a telemetry system would enable collection of bearings in a timely manner while minimizing error from manual input of receiver location coordinates and time and date. Researchers should strive to maximize precision, accuracy, and efficiency of telemetry systems so as to generate the best data possible on freeranging wildlife.

Our goal was to develop a more efficient and effective integrated vehicle-mounted VHF-based telemetry system that combines the latest technologies in electronic equipment in a practical and efficient arrangement for collecting telemetry data. Our objectives were to test accuracy, precision, and efficiency of our integrated vehicle-mounted telemetry system.

\section{STUDY AREA}

We conducted our study in 2 areas of Nebraska, USA, representing numerous habitat types. The first area was at DeSoto National Wildlife Refuge (DNWR), located $30 \mathrm{~km}$ 
north of Omaha, Nebraska in the Missouri River valley of eastern Nebraska and western Iowa, USA. The DNWR was a 3,385-ha mosaic of deciduous forest, grassland, agricultural, and wetland habitats with minimal change in elevation (302-306 m). The forest consisted of eastern cottonwood (Populus deltoides), mulberry (Morus rubra), rough-leafed dogwood (Cornus drummondii), poison ivy (Rhus radicans), and common scouring-rush (Equisetum hyemale). Grassland habitat included warm- and cool-season grasses such as big bluestem (Andropogon gerardii), little bluestem (Schizachyrium scoparium), Indiangrass (Sorghastrum nutans), switchgrass (Panicum virgatum), smooth brome (Bromus inermis), and western wheatgrass (Agropyron smithii). Corn and soybeans were the main cultivated agricultural crops on DNWR.

The second area was located about $500 \mathrm{~km}$ west in the North Platte River valley of Morrill County in the panhandle of western Nebraska. The landscape consisted of riparian, agricultural, and short-grass prairie habitats. Major land uses were ranching and irrigated farming. The change in elevation of the area ranged from little in the river corridor to abrupt changes in elevation in the breaks above the river valley $(1,100-1,350 \mathrm{~m})$, with gentle rolling hills in the prairie regions. Riparian areas were dominated by eastern cottonwood and Russian-olive (Elaeagnus angustifolia). The prairie consisted mostly of blue grama (Bouteloua gracilis), buffalo grass (Buchloe dactyloides), little bluestem, and western wheatgrass. Corn, wheat, and alfalfa were the main irrigated crops.

\section{METHODS}

We designed and built 2 integrated vehicle-mounted telemetry systems. The systems incorporated a 9-element, vertically polarized, directional Yagi antenna (model PLC 1509; Cushcraft Corporation, Manchester, NH), electronic compass (model C100; KVH Industries, Middletown, RI), GPS unit, and laptop computer (Toughbook 29; Panasonic, Secaucus, NJ; Fig. 1). The antenna mast was constructed of an aluminum pole $(3.8-\mathrm{cm}$ outside diam, $0.6-\mathrm{cm}$ wall) held in place with 2 insert bearings $(3.8-\mathrm{cm}$ inside diam), one in the roof of the vehicle and the other in the mast stand inside the cab of the vehicle (Fig. 2). We mounted the computer on a base plate and screen support stand with a pole assembly, swivel attachment, and vibration plate (Gamber Johnson, Stevens Point, WI) to protect it from vibration, jarring, and daily wear.

We custom-built the mast stands for each vehicle and constructed them with a length of $10-\mathrm{cm}$ square tube steel welded to a piece of flat steel $(0.48 \mathrm{~cm} \times 10 \mathrm{~cm} \times 91 \mathrm{~cm})$ shaped to fit the interior of the vehicle (Fig. 2). We welded an insert-bearing flangette to the top end of the square tube steel. We concealed one insert-bearing in the mast stand, which provided support and permitted smooth and easy rotation of the antenna mast. A second top flangette secured the insert-bearing in the mast stand and 4 bolts held the flangettes together. We welded a threaded pipe connection to the top flangette to which we attached a piece of sheet metal to support a full-circle protractor. The threaded pipe connection allowed the protractor to be rotated. We mounted the second insert bearing in the roof of the vehicle, supported by 2 flangettes and we attached it to the sheet metal of the roof, which provided additional support and rotation for the antenna mast (Fig. 2). We sealed and prelubricated the insert bearings. We used a pin through the mast stand and antenna mast to prevent the antenna from rotating while the vehicle was moving. To keep precipitation from getting into the vehicle, we used silicon to seal the bolts and flangette on the roof of the vehicle. We also attached a piece of rubber on the antenna mast $4 \mathrm{~cm}$ above the insert bearing that acted as a rain shield to prevent direct contact of precipitation on the insert bearing and bolts.

We attached the housed C100 compass to the top of the aluminum mast $81 \mathrm{~cm}$ above the top of the vehicle. We concealed the wiring cables from the compass and directional antenna inside the mast leading into the cab where the antenna cable was attached to the telemetry receiver and the compass cable was attached to a liquid crystal display. We filled all holes in the exterior portion of the antenna mast with silicon to make them weatherproof.

We equipped the GPS unit with an external antenna to obtain the best possible satellite reception. We mounted the magnetic external antenna on the top of the cab of the vehicle. We routed the cable for the external antenna through a silicon-sealed hole in the back of the cab and attached it to the GPS unit. We mounted the GPS unit in a RAM mount (RAM Mounts, Seattle, WA) attached to the antenna mast stand (Fig. 1). We connected the GPS unit to the computer through a serial port.

We used Location of a Signal (LOAS) software (Version 4.0; Ecological Software Solutions, Urnäsch, Switzerland) to analyze telemetry data and to display results. The LOAS program had real-time GPS capabilities by communicating with the GPS unit connected via the serial port of the computer. The user initiated communication between the software and GPS unit by selecting user-defined parameters. The LOAS software contained a testing option to enter the actual GPS location of test transmitters. To collect telemetry data, the observer imported the receiver location ( $x$ - and $y$-coordinates of the location of the vehicle) from the GPS and the date and time information from the computer into the spreadsheet by pressing the F6 key. The observer then manually entered an animal identification and a bearing to the transmitter into the spreadsheet. The observer selected the appropriate output variables (e.g., Estimated Locations, Ellipse Area, Error Angles, Location Error Distance) to determine precision and accuracy of the telemetry system. We used the Error Angles and Location Error Distance parameters to determine precision and accuracy of the telemetry system, respectively. We used the maximum likelihood estimator to calculate the estimated locations and the $95 \%$ chi-square confidence distribution to compute error polygons. We recorded the time needed from start to finish to generate each telemetry 


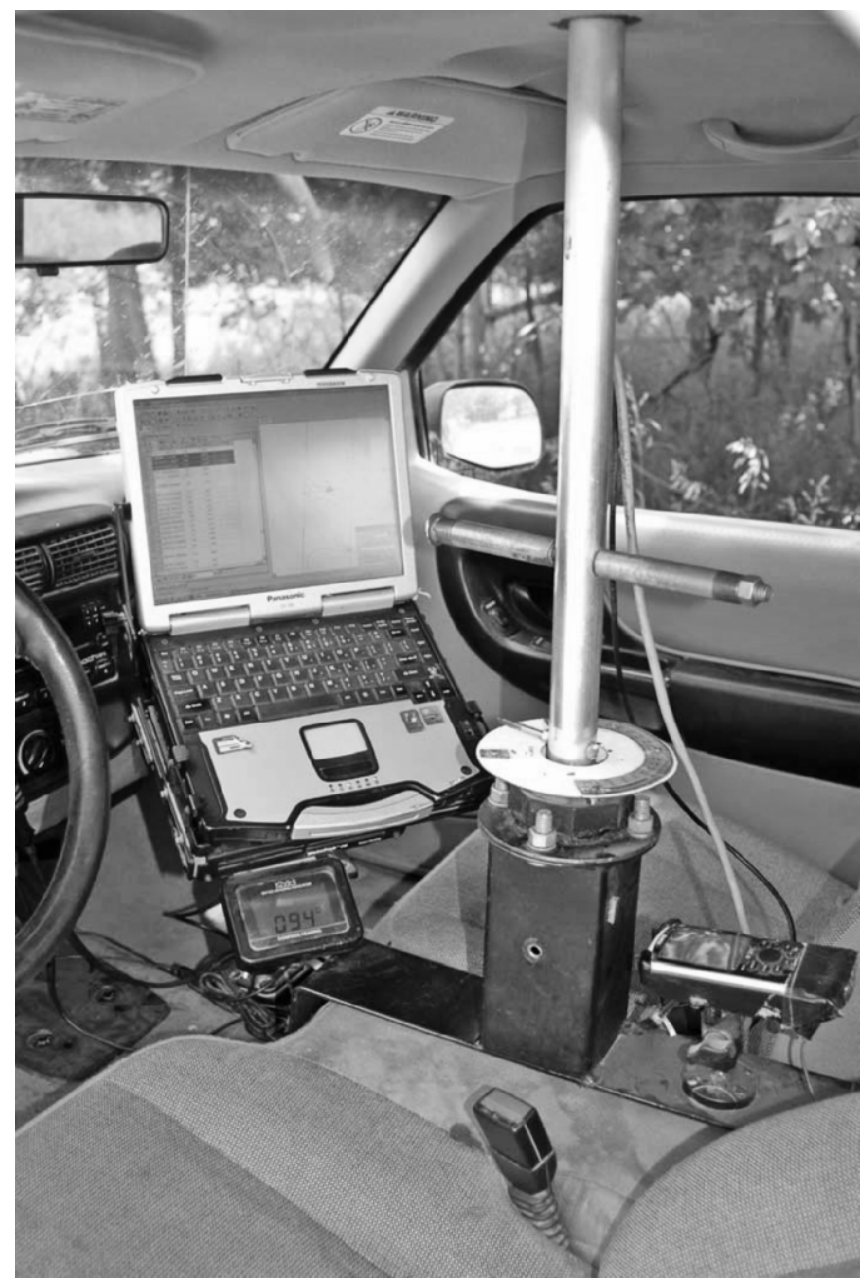

Figure 1. Integrated vehicle-mounted telemetry system showing primary components, tested in Nebraska, USA.

bearing, estimate transmitter location, and to enter data for each transmitter.

We used a different vehicle, telemetry system, and observer at each site to evaluate precision, accuracy, and efficiency of the telemetry system. We calibrated the compass in each vehicle for the respective study area, based on manufacturer instructions, to account for magnetic declination specific to each area. We placed 5 white-tailed deer-sized radiocollars (150.00-151.99 MHz; Advanced Telemetry Systems, Isanti, MN) in open habitat (agricultural or short-grass fields), 5 in mixed habitat (i.e., tallgrass or shrubs $>1 \mathrm{~m}$ in ht), and 5 in wooded habitat. We placed transmitters $1 \mathrm{~m}$ aboveground on stakes in a stratified manner at $150-\mathrm{m}$ intervals out to about $1 \mathrm{~km}$ perpendicular to the path traveled by the observer. We measured the distance from the centrally located receiver location with a Trimble ${ }^{\circledR}$ GeoXM $^{\mathrm{TM}}$ GPS unit and randomly placed the transmitters $0-50 \mathrm{~m}$ left or right of an imaginary line perpendicular to the path traveled by the observer in the vehicle. An assistant placed the radiotransmitters in the appropriate habitat at the appropriate distance and recorded the location of each transmitter with the GPS unit. At each habitat type, a naive observer collected telemetry locations

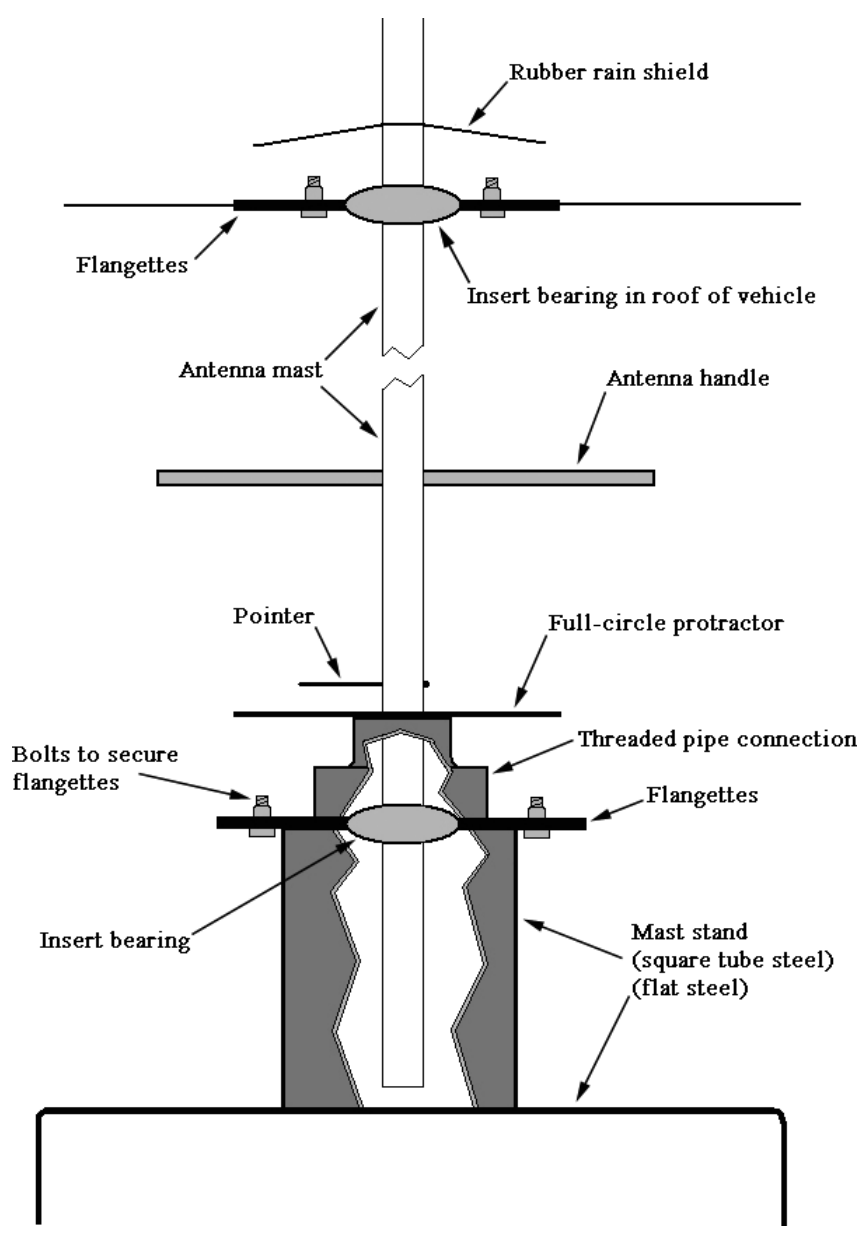

Figure 2. Cutaway illustration of antenna mast-stand components inside the cab of an integrated vehicle-mounted telemetry system, tested in Nebraska, USA.

for all transmitters at 5 receiver locations about $200 \mathrm{~m}$ apart along a straight stretch of road. Each observer recorded 5 azimuths/transmitter to solve the location of the radiocollar; 3 azimuths that yielded the smallest error polygon were used to estimate the transmitter location.

\section{RESULTS}

The total cost of materials for each vehicle-mounted telemetry system was $\$ 7,349$ (United States currency; Table 1). Throughout our study areas, average estimated error reported by our GPS ranged from $2.01 \mathrm{~m}$ to $10.67 \mathrm{~m}$ and varied depending on habitat type. Precision of our system (i.e., mean difference between actual and recorded bearings to the transmitter from the respective receiver location) was $2.63 \pm 12.13^{\circ}\left(\mathrm{SD}\right.$; range $\left.=-33.7-42 \cdot 2^{\circ}\right)$. Accuracy of our system (i.e., mean linear distance between actual and estimated transmitter location) was $128 \pm 91.3 \mathrm{~m}$ (SD; range $=0-408 \mathrm{~m}$ ). Mean time for observers to record 5 azimuths from 5 locations and their associated Universal Transverse Mercator coordinates over a 1-km section of road was 6.28 minutes. Mean distance from receiving locations to test transmitters was $574 \pm 258.6 \mathrm{~m}(\mathrm{SD}$; range $=116-1,346$ 
Table 1. Itemized list of materials required to build the integrated vehiclebased telemetry system (United States dollars as of 2006), tested in Nebraska, USA.

\begin{tabular}{lc}
\hline \multicolumn{1}{c}{ Item } & Cost (\$) \\
\hline Field computer (Toughbook ${ }^{\circledR} 29$ with Touchscreen; & 4,500 \\
$\quad$ Panasonic, Secaucus, NJ) & 75 \\
Location of a Signal (Ecological Software Solutions, & \\
$\quad$ Urnäsch, Switzerland) & 1,100 \\
Electronic compass (C100 with display; & 420 \\
$\quad$ KVH Industries, Middletown, RI) & \\
Global Positioning System (GPS; Garmin GPS 76 & 600 \\
$\quad$ with external antenna, interface cables, mount) & \\
Vehicle computer mount (Gamber Johnson, & 210 \\
$\quad$ Stevens Point, WI) & 76 \\
Antenna (model PLC 1509; Cushcraft Corporation, & \\
$\quad$ Manchester, NH) & 54 \\
Antenna mast (1.8 m long, 3.8 cm outside diam, & 22 \\
$\quad$ 0.6-cm wall thickness) & 5 \\
Insert bearings (3.8 cm inside diam, 2 @ \$27/bearing) & 10 \\
Insert bearing flangettes (2 @ \$11/pair) & 77 \\
Full-circle protractor & 200 \\
Steel for mast stand (0.48 cm $\times 10$ cm $\times 91$ cm) & \\
Compass (Sightmaster ${ }^{\mathrm{TM}} 360 \mathrm{LA}$; Brunton, Riverton, WY) & \\
Miscellaneous (e.g., coaxial cable, stainless steel fasteners, & \\
$\quad$ silicone, handle, rubber rainshield pointer) & 7,349 \\
Total cost of system (excluding vehicle and labor) &
\end{tabular}

m). All triangulations used to estimate location of test transmitters were determined by error polygons of $\leq 1$ ha.

\section{DISCUSSION}

The VHF-based integrated telemetry system we designed, built, and tested allowed the observer to efficiently enter data into a spreadsheet, estimate the location of radiomarked animals, and confirm and accept each location, all while in the field. Previous methods for collecting VHFbased radiotelemetry data involved tedious collection and manipulation of data by multiple steps including collecting telemetry data in the field, entering telemetry data into a spreadsheet or database, solving telemetry data, and importing estimated location data into a Geographic Information System (GIS). The more the data is manipulated, the greater the chance of introducing human and system errors. With our system, observers solve the data in the field and visually discern the animal's location relative to the habitat. By immediately solving telemetry data on the computer, observers see the receiver locations, telemetry azimuths, error polygon, and estimated location for each animal relative to the local environment. If an unacceptable location estimate is obtained (e.g., large error polygon, unreasonable location), the observer can collect additional telemetry bearings, recalculate, and obtain a satisfactory estimate of location. Data collected with our integrated telemetry system are electronic and ready for input into other GIS software.

Precision of our system $\left(\bar{x}=2.63^{\circ}\right)$ was similar to previous VHF-based telemetry studies (range $=1-16^{\circ}$; Marzluff et al. 1997, Brinkman et al. 2002, Cox et al. 2002) but our accuracy $(\bar{x}=128 \mathrm{~m})$ was better than that reported from studies on mammals using handheld antennae or compasses (range $=183-476$ m; Horner and Powell 1990, Kauhala and
Tiilikainen 2002, Jones and Pelton 2003, Storlie 2006, Walter et al. 2006). Our precision was likely influenced by the habitats in which we placed test transmitters and by bounced signals that are common to radiotelemetry studies (Lee et al. 1985, White and Garrott 1990). To our knowledge, our location error distance and time needed to record 5 azimuths for estimating a location were less than any other mobile telemetry system. Although habitat configuration and road networks at a site dictate time needed to triangulate radiolocations, our system is more efficient in collecting locations because researchers do not need predefined receiving stations and can get as close to the study animal as conditions at the study site will allow. The importance of this efficient system may be of additional value to studies that involve highly mobile species, because differences in accuracy have been documented for modulating and nonmodulating transmitters (Lee et al. 1985).

The LOAS program allowed users to select custom parameters to fit research needs and contained script for testing telemetry systems using known locations of test transmitters. The software included 17 data output fields that can be used to display and analyze precision and accuracy of telemetry systems. We worked closely with personnel from Ecological Software Solutions over the past 3 years to test new script and locate deficiencies in the LOAS program. Software designers have upgraded LOAS 4 times since 2004 to suit the needs of such a telemetry system. The LOAS program was compatible with the Toughbook ${ }^{\circledR}$ series of Panasonic field laptop computers, which are built to withstand vibration, dust, moisture, and other abuse encountered in field conditions. Our field computers included an optional Touchscreen that made computer operation more efficient and user-friendly. We have used 3 Toughbooks for 4 years and have had no malfunctions while collecting $>15,000$ locations. Comparatively, a standard laptop in a vehicle failed after 2 weeks due to failure of the fan.

Magnetic materials close to the electronic compass can cause erroneous azimuth readings. Product instructions for the $\mathrm{C} 100$ suggest mounting the compass engine $\geq 30.5 \mathrm{~cm}$ from any material that may contain magnetic interference (i.e., magnetic metal) to obtain the highest level of accuracy. Our antenna and mast were constructed of aluminum and we used stainless steel fasteners to attach the antenna and compass to the mast. Aluminum and stainless steel are nonmagnetic; therefore, no magnetic materials were within $30.5 \mathrm{~cm}$ of the compass. The closest magnetic material was the roof of the vehicle, which was $81 \mathrm{~cm}$ below the compass. We included a full-circle protractor on a rotating platform and a sight-through compass (Sightmaster ${ }^{\mathrm{TM}}$, Brunton, Riverton, WY) in the vehicle that served as a backup should the electronic compass fail or if we encountered areas with excessive magnetic interference (e.g., near overhead power lines). In 15 years of using electronic compasses, we did not experience any failures that forced us to use the handheld compass.

The height of the antenna and compass above the vehicle was not obtrusive enough to restrict movement through 
wooded habitat. The overall height of our vehicle and antenna was $2.84 \mathrm{~m}$ above ground. As with all high-profile vehicles, operators must be aware of other overhead obstructions such as low-hanging electrical wires to avoid possible electrocution and damage to equipment. Our 9element antenna was more accurate for locating our VHF frequency range (i.e., 150-152 MHz) and in habitats with more vertical structure (i.e., forests; Fuller et al. 2005). However, depending on study-specific characteristics, the antenna type, mounting platforms, and collapsible antenna designs (i.e., for ease of transport) could be incorporated into our design without negatively affecting the reliability of our integrated system (Brinkman et al. 2002, Cox et al. 2002).

\section{Management Implications}

Because of the expense and small sample size often associated with GPS radiocollars, measures to improve telemetry studies that use traditional VHF-based radiocollars are needed. Our integrated vehicle-mounted antenna system can provide accuracy and efficiency lacking in handheld or previous vehicle-mounted telemetry systems. The electronic compass provides a more accurate estimate of bearings for locating wildlife and the computer and GPS within the vehicle increases efficiency in collecting geographic coordinates and estimating locations in the field. Signal bounce, common to all radiotelemetry studies, can be assessed in the field and additional bearings can be collected to get more accurate estimates of location for free-ranging wildlife. The accuracy and efficiency of our system makes it ideal for radiotelemetry studies that involve highly mobile species or for locating species during periods of high activity (i.e., dispersal, migration, daily movements).

\section{Acknowledgments}

We were funded by the National Wildlife Research Center of the United States Department of Agriculture, Animal and Plant Health Inspection Service, Wildlife Services; University of Nebraska-Lincoln Research Council, Institute of Agriculture and Natural Resources and the Integrated Pest Management-Vertebrates Program; United States Fish and Wildlife Service; Nebraska Game and Parks Commission; Nebraska Bowhunters Association; and Berryman Institute for Wildlife Damage Management. We thank K. L. Sallee of Ecological Software Solutions who was instrumental in the development of Location of a Signal software for this telemetry system. We also thank L. Klimek, B. Barry, M. Sheets, and other personnel at DeSoto National Wildlife Refuge for providing study sites, equipment, assistance, maintenance, lodging, and camaraderie necessary for the study. M. Cover and W. Herman assisted in designing and constructing the mast stands and C. Frost, T. Kinsell, C. Luedtke, and R. Otto assisted with maintenance of the telemetry systems.

\section{LITERATURE CITED}

Bertrand, M. R., A. J. DeNicola, S. R. Beissinger, and R. K. Swihart. 1996. Effects of parturition on home ranges and social affiliations of female white-tailed deer. Journal of Wildlife Management 60:899-909.
Brinkman, T. J., C. S. DePerno, J. A. Jenks, J. D. Erb, and B. S. Haroldson. 2002. A vehicle-mounted radiotelemetry antenna system design. Wildlife Society Bulletin 30:258-262.

Cochran, W. W., and R. D. Lord, Jr. 1963. A radio-tracking system for wild animals. Journal of Wildlife Management 27:9-24.

Cox, R. R., Jr., J. D. Scalf, B. E. Jamison, and R. S. Lutz. 2002. Using an electronic compass to determine telemetry azimuths. Wildlife Society Bulletin 30:1039-1043.

D'eon, R. G., R. Serrouya, G. Smith, and C. O. Kochanny. 2002. GPS radiotelemetry error and bias in mountainous terrain. Wildlife Society Bulletin 30:430-439.

Etter, D. R., K. M. Hollis, D. R. Ludwig, J. E. Chelsvig, and C. L. Anchor. 2002. Survival and movements of white-tailed deer in suburban Chicago, Illinois. Journal of Wildlife Management 66:500-510.

Fuller, M. R., J. J. Millspaugh, K. E. Church, and R. E. Kenward. 2005. Wildlife radiotelemetry. Pages $377-417$ in C. E. Braun, editor. Techniques for wildlife investigations and management. The Wildlife Society, Bethesda, Maryland, USA.

Grund, M. D., J. B. McAninch, and E. P. Wiggers. 2002. Seasonal movements and habitat use of female white-tailed deer associated with an urban park. Journal of Wildlife Management 66:123-130.

Horner, M. A., and R. A. Powell. 1990. Internal structure of home ranges of black bears and analyses of home-range overlap. Journal of Mammalogy 71:402-410.

Jones, M. D., and M. R. Pelton. 2003. Female American black bear use of managed forest and agricultural lands in coastal North Carolina. Ursus 14:188-197.

Jones, M. L., N. E. Mathews, and W. F. Porter. 1997. Influence of social organization on dispersal and survival of translocated female white-tailed deer. Wildlife Society Bulletin 25:272-278.

Kauhala, K., and T. Tiilikainen. 2002. Radio location error and estimates of home-range size, movements, and habitat use: a simple field test. Annales Zoologi Fennici 39:317-324.

Lee, J. E., G. C. White, R. A. Garrott, R. M. Bartmann, and A. W. Alldredge. 1985. Accessing accuracy of a radiotelemetry system for estimating animal locations. Journal of Wildlife Management 49:658663.

LeMunyan, C. D., W. White, E. Nyberg, and J. J. Christian. 1959. Design of a miniature radiotransmitter for use in animal studies. Journal of Wildlife Management 23:107-110.

Lovallo, M. J., K. C. Vercauteren, N. C. Hedge, E. M. Anderson, and S. E. Hygnstrom. 1994. An evaluation of electronic versus hand-held compasses for telemetry studies. Wildlife Society Bulletin 22:662667.

Marzluff, J. M., B. A. Kimsey, L. S. Schueck, M. E. McFadzen, M. S. Vekasy, and J. C. Bednarz. 1997. The influence of habitat, prey abundance, sex, and breeding success on the ranging behavior of prairie falcons. Condor 99:567-584.

Mooty, J. J., P. D. Karns, and T. K. Fuller. 1987. Habitat use and seasonal range size of white-tailed deer in north-central Minnesota. Journal of Wildlife Management 51:644-648.

Nelson, M. E., and L. D. Mech. 1984. Home-range formation and dispersal of deer in northeastern Minnesota. Journal of Mammalogy 65: 567-575.

Nelson, M. E., and L. D. Mech. 1999. Twenty-year home-range dynamics of a white-tailed deer matriline. Canadian Journal of Zoology 77:11281135 .

Ozoga, J. J., and L. J. Verme. 1975. Activity patterns of white-tailed deer during estrus. Journal of Wildlife Management 39:679-683.

Ozoga, J. J., L. J. Verme, and C. S. Bienz. 1982. Parturition behavior and territoriality in white-tailed deer: impact on neonatal mortality. Journal of Wildlife Management 46:1-11.

Storlie, J. T. 2006. Movements and habitat use of female Roosevelt elk in relation to human disturbance on the Hoko and Dickey Game Management Units, Washington. Thesis, Humboldt State University, California, USA.

Storm, D. J., C. K. Nielsen, E. M. Schauber, and A. Woolf. 2007. Space use and survival of white-tailed deer in an exurban landscape. Journal of Wildlife Management 71:1170-1176.

Vercauteren, K. C., and S. E. Hygnstrom. 1998. Effects of agricultural activities and hunting on home ranges of female white-tailed deer. Journal of Wildlife Management 62:280-285. 
Walter, W. D., D. M. Leslie, Jr., and J. A. Jenks. 2006. Response of Rocky Mountain elk (Cervus elaphus) to wind-power development. American Midland Naturalist 156:363-375.

White, G. C., and R. A. Garrott. 1990. Analysis of wildlife radiotracking data. Academic Press, San Diego, California, USA.

Withey, J. C., T. D. Bloxton, and J. M. Marzluff. 2001. Effect of tagging and location error in wildlife radiotelemetry studies. Pages 43-75 in J. J.
Millspaugh and J. M. Marzluff, editors. Radiotracking and animal populations. Academic Press, San Diego, California, USA.

Zimmerman, J. W., and R. A. Powell. 1995. Radiotelemetry error: location error method compared with error polygons and confidence ellipses. Canadian Journal of Zoology 73:1123-1133.

Associate Editor: Conner. 